\title{
Risk factors for hepatitis B virus infection among adult Nigerians with clinical features of liver diseases in a resource-constrained environment of a primary care clinic in Eastern Nigeria
}

\author{
Gabriel Uche Pascal Iloh ${ }^{1,}$, Abali Chuku², Agwu Nkwa Amadi ${ }^{3}$, Nnadozie Paul Obiegbu ${ }^{4}$ \\ ${ }^{1}$ Department of Family Medicine, Federal Medical Centre, Umuahia, Abia state, Nigeria \\ ${ }^{2}$ Department of Ophthalmology Federal Medical Centre, Umuahia, Abia state, Nigeria \\ ${ }^{3}$ Department of Public Health Technology, Federal University of Technology, Owerri, Imo state, Nigeria \\ ${ }^{4}$ Ministry of Health, Awka, Anambra State, Nigeria and Trainer in Family Medicine program, Federal Medical Centre, Owerri, Nigeria
}

\section{Email address:}

ilohgup2009@yahoo.com(G. U. P. Iloh)

\section{To cite this article:}

Gabriel Uche Pascal Iloh, Abali Chuku, Agwu Nkwa Amadi, Nnadozie Paul Obiegbu. Risk Factors For Hepatitis B Virus Infection Among Adult Nigerians With Clinical Features Of Liver Diseases In A Resource-Constrained Environment Of A Primary Care Clinic In Eastern Nigeria. Science Journal of Clinical Medicine. Vol. 2, No. 3, 2013; pp. 98-105. doi: 10.11648/j.sjcm.20130203.17

\begin{abstract}
Background: Hepatitis B virus (HBV) infection is an important contributor to the burden of liver diseases in adult Nigerians and constitutes a threat to socio-economic development in the sub-region. Screening for its risk factors in patients with clinical features of liver diseases is an important primary care challenge that is often neglected. Aim: To determine the risk factors for HBV infection in adult Nigerians with clinical features of liver diseases in a resourceconstrained environment of a primary care clinic in Eastern Nigeria. Materials and Methods: A cross sectional study was carried out on 140 adult Nigerians with clinical features of liver diseases at the primary care clinic of a tertiary hospital in Nigeria. Clinical features of liver diseases were based on the presence of some constitutional, hepatic and extra-hepatic features. Hepatitis B surface antigen (HBsAg) was assayed using immunochromatographic method. A pre-tested, structured interviewer-administered questionnaire was used to obtain socio-demographic variables and histories of HBV-related risk factors. Results: The HBV sero-prevalence was $50.7 \%$. The age group $40-60$ years $(\mathrm{P}=0.048)$ and artisans $(\mathrm{P}=0.019)$ were significantly infected. The behavioural risk factors significantly associated with $\mathrm{HBV}$ infection were histories of unprotected sexual exposures $(\mathrm{P}=0.001)$, blood transfusion $(\mathrm{P}=0.022)$ and non-hepatitis $\mathrm{B}$ vaccination $(\mathrm{P}=0.030)$. The most significant predictor of $\mathrm{HBV}$ infection was history of unprotected sexual exposures $(\mathrm{OR}=5.04, \mathrm{P}=0.003)$. Conclusion: Risk factors of HBV infection exist in adult Nigerian patients with clinical features of liver diseases and HBV infection was significantly associated with age, occupation, unprotected sexual exposures, blood transfusion and non-hepatitis B vaccination.
\end{abstract}

Keywords: Hepatitis B Surface Antigen Sero-Marker, Liver Diseases, Nigeria, Primary Care Clinic, Risk Factors

\section{Introduction}

Globally, hepatitis B virus (HBV) - related liver diseases are recognized as an important public health problem particularly in high endemic regions of sub-Saharan Africa, China and South-East Asia. ${ }^{[1,2]}$ The prevalence of HBV infection varies geographically throughout the world from high $(>8 \%)$, intermediate $(2-7 \%)$ to low $(<2 \%)$ prevalence rates. ${ }^{[2]}$ About 2 billion people have been infected whilst about 360 million people are chronic carriers, harbouring the virus in their liver and blood. ${ }^{[3]}$ However, in subSaharan African countries, HBV infection has been one of the preventable causes of morbidity and mortality and a threat to socio-economic development in the sub-region. ${ }^{[4,5]}$

Variable frequencies of HBV-induced liver diseases have been reported throughout the world, ${ }^{[6-9]}$ although higher in developing countries such as Nigeria where it is hyper endemic $^{[4,5,10,11]}$ In Nigeria, about 18 million people are infected chronically ${ }^{[12]}$ and prevalence of HBsAg has been reported in various parts of the country: $10.3 \%$ was 
reported in urban community in Jos, Nigeria ${ }^{[12]}, 12.6 \%$ was reported in rural community in Northern Nigeria ${ }^{[13]}$ and $14.5 \%$ reported in hospital patients in Port Harcourt, Nigeria. ${ }^{[14]}$ Research findings in Nigeria have also shown that HBV infection is one of the aetiological agents of liver diseases ${ }^{[10,15-17]}$ and liver diseases have also been found to be prevalent in HBV infection endemic areas of Nigeria. ${ }^{[18-}$

${ }^{21]}$ In Maiduguri, Northern Nigeria, HBsAg prevalence of $49 \%, 56 \%$ and $50 \%$ were detected among patients with HBV-related hepatitis, liver cirrhosis and hepatocellular carcinoma respectively. ${ }^{[19]}$ Similarly, in Lagos, Southern Nigeria, the reported frequencies were $14 \%, 30 \%$ and $56 \%$ for HBV-related hepatitis, liver cirrhosis and hepatocellular carcinoma respectively. ${ }^{[20]}$ However in other parts of the world such as Bangladesh, HBsAg prevalence of $19 \%$ was reported among hepatitis patients ${ }^{[22]}$ and $47 \%$ in hepatocellular carcinoma patients. ${ }^{[23]}$

The prevalence of HBV infection, human behaviour and socio-cultural practices conspire to mould geographical differences in the epidemiological pattern. ${ }^{[2]}$. Epidemiological studies in areas of high HBV endemicity have shown that perinatal transmission is reportedly the predominant route of transmission whereas in areas of low endemicity, sexual contact among high risk persons is the main route. ${ }^{[2,24]}$ However, HBV transmission in adults through sexual and percutaneous mechanism have been described in high endemic areas of Nigeria, $\left.{ }^{[25,26}\right]$ Egypt $^{[27]}$ and other parts of the world like Bangladesh ${ }^{[28]}$ and Bucharest. ${ }^{[29]}$

In Nigeria, there is absence of research study on the relative distribution of risk factors of $\mathrm{HBV}$ infection and increasing number of adult Nigerians patients presenting with HBV-related hepatocellular cancers. ${ }^{[5,18-21]}$ However, the vulnerable demographic and behavioural risk factors of these patients with clinical features of liver disease may have contributed to the acquisition of HBV infection. It is against this background that the authors aimed at determining the risk factors for $\mathrm{HBV}$ infection in adult Nigerians with clinical features of liver diseases in a resource-constrained environment of a primary care clinic in Eastern Nigeria.

\section{Materials and Methods}

\subsection{Ethical Approval}

Ethical certificate was obtained from the Ethics Committee of the hospital. Informed consent was obtained from patients.

\subsection{Study Design}

This was a clinic-based cross-sectional study on adult Nigerians with clinical features of liver diseases carried out from June 2006 and June 2007 at the department of Family Medicine of a tertiary hospital in Eastern, Nigeria. This study design didn't employ apriori separate control group.
However, the authors controlled for the patients with risk factors of $\mathrm{HBV}$ infection using those without the risk factors of $\mathrm{HBV}$ infection within the study population.

\subsection{Study Setting}

Federal Medical Centre, Owerri is located in the municipal city of Owerri. It is a tertiary hospital established with the tripartite mandate of service delivery, training and research and serves as a referral centre for primary and secondary public health institutions as well as missionary and private hospitals in Imo State and neighbouring States of Abia, Ebonyi, Rivers and Akwa Ibom States of Nigeria.

The department of Family Medicine serves as a primary care clinic within the tertiary hospital setting of the Medical Centre. All patients excluding paediatric patients and antenatal women are first seen at the department of Family Medicine where diagnoses are made. Patients who need primary care are managed and followed up in the clinic while those who need other specialists care are referred to the respective core specialist clinics for further management. The clinic is run by Consultant Family Physicians and postgraduate resident doctors in Family Medicine.

\subsection{Inclusion and Exclusion Criteria}

The inclusion criteria were patients aged $\geq 15$ years who gave informed consent and had clinical features of liver diseases. The exclusion criterion included pregnant patients and critically ill patients.

\subsection{Sample Size Determination}

The sample size $(\mathrm{N})$ was calculated using the formula ${ }^{[30]}$ $\mathrm{N}=[(\mathrm{Z} \alpha+\mathrm{Z} \beta) \times 2 \mathrm{pq}] / \mathrm{d}^{2}$ Where $\mathrm{N}=$ Desired sample size, $\mathrm{Z}=$ The standard normal deviate set at 1.96 which correspond to $95 \%$ confidence level $\mathrm{P}=$ Prevalence of the HBV infection, $\mathrm{q}=1.0-\mathrm{p}$, and $\mathrm{d}=$ degree of precision desired set at 0.05 The level of significance was set at $5 \%(\alpha=0.05)$ while the power of the $\operatorname{study}(1-\beta)$ was set at $80 \%$. A prevalence of $38 \%$ was used based on previous study in Maiduguri, Nigeria. ${ }^{[19]} \mathrm{N}=[(1.96 \times 0.05+1.96 \times 0.20)$ $\mathrm{x} 2 \mathrm{x} 0.38 \mathrm{x} 0.62] / 0.05^{2} \mathrm{~N}=92$

The calculated minimum sample size was 92 . However, to improve the precision of the study, the estimated sample size $=\mathrm{Ns}$ was determined considering an anticipated response rate of $90 \%(0.9)$. The estimated sample size (Ns) was determined by dividing the original calculated sample size $(\mathrm{N})$ by the anticipated response rate ${ }^{[31]}$ as follows, $\mathrm{Ns}=$ $\mathrm{N} / 0.9$, where $\mathrm{N}=$ Minimum calculated sample size, $\mathrm{Ns}=$ Selected sample size, anticipated response rate $=0.9$. Thus, the estimated sample size $=92 / 0.9=102$. However, a sample size of 140 patients was used based the proposed duration of the study.

\subsection{Sampling Technique}

The sample selection was done consecutively using 
every adult patient who had clinical features of liver diseases. This sampling technique was judgmentally chosen by the authors. ${ }^{[31]}$

\subsection{Methods}

The demographic variables collected from the study population included age, sex, marital status, education and occupation. The social classification of patients was into lower, middle and upper occupational classes to suit Nigerian environment. ${ }^{[32]}$

A structured, pre-tested and interviewer administered questionnaire was use to obtain information on HBVrelated risk factors. The risk factors included sexual factor (history of unprotected sexual exposures), parenteral factor (history of transfusion of infected blood), percutaneous factors (history of use of unsterilized sharp instruments for various purposes), family history of HBV infection and history of hepatitis B vaccination.

The pre-testing of the questionnaire was done internally at the tertiary hospital using five patients with clinical features of liver disease who met the selection criteria and externally at St Damian Hospital, a General Hospital in Orlu, Imo state, Nigeria using five patients with clinical features of liver diseases who met the selection criteria. The pre-testing of the questionnaire lasted for two weeks at the two hospitals respectively. The respondents for the pretesting were selected haphazardly and those used from the study hospital were excluded from the main study. The pretesting was done to find out how the questionnaire would interact with the respondents and ensure that there were no ambiguities.

\section{Diagnostic Procedures}

Patients with clinical features of liver diseases were offered hepatitis B surface antigen test after informed verbal explanation and consent. Two milliliters of venous blood were collected from each patient from the antecubital fossa after thorough aseptic cleaning. The whole venous blood was tested for hepatitis B surface antigen using the commercially available rapid sero-diagnostic kits, one step test strip manufactured by ACON laboratories, Inc. 4108 Sorrento valley, San Diego, United State of America. The test strip uses whole blood, serum or plasma. The dipstick test strip is a rapid, qualitative, one step immunoassay based on the immunochromatographic principle (ICP). This method employs unique combinations of monoclonal dye conjugate (colloidal gold) and polyclonal solid phase antibodies to selectively identify hepatitis B surface antigen with high specificity and sensitivity. The test kit has sensitivity of $99.9 \%$ and specificity of $100 \%$. Manufacturer's standard operating procedures were strictly followed.

\subsection{Diagnostic Criteria}

Patients with clinical features of liver disease present with constitutional, hepatic and extra-hepatic features ${ }^{[28,29]}$ which were grouped into three. Histopathological examination was not performed. The three groups were:

Group 1(Hepatitis patients): These were patients with hepatitis with the clinical features of fever, anorexia, nausea, malaise, fatigue, dark urine, pale stool, pruritus, joint pain, jaundice, right upper quadrant abdominal pain and tender hepatomegaly.

Group 2(Liver cirrhosis patients): This group was made up of patients with liver cirrhosis who had clinical features of fatigue, malaise, weight loss, abdominal swelling, pruritus, jaundice, reduced liver span, ascites, splenomegaly, pedal edema, muscle wasting, varicel bleeding, spider naevi, gynaecomastia and testicular atrophy in men.

Group 3(Hepatocellular carcinoma patients): This group consisted of patients with hepatocellular carcinoma who had clinical features of anorexia, nausea and vomiting, marked weight loss, marked abdominal swelling, jaundice, marked muscle wasting, irregular and hard liver, a bruit or friction rub over the liver on auscultation, marked ascites, hepatomegaly and marked pedal edema.

Operational definition of terms.

The authors defined risk factors of HBV infection as antecedent condition(s) whose presence is(are) positively associated with an increased probability that HBV-related disease will develop later or that the prognosis of an existing HBV-related liver disease will progressively worse. Behavioral risk factors of $\mathrm{HBV}$ infection refers to the activities which predispose a person to acquiring HBV infection including sexual activities with infected person, use of unsterilized and contaminated sharp instruments for various purposes, transfusion of infected blood and health services utilization behavior like hepatitis B vaccination. High endemicity of HBV infection means prevalence of HBsAg $>8 \%$. Hepatitis $\mathrm{B}$ vaccination refers to the receival of complete doses of hepatitis $\mathrm{B}$ vaccine. Artisans refer to manual workers and include masons (bricklayers), fitter mechanics, electricians, tailors, seamstresses, hair dressers and carpenters.

\subsection{Statistics}

The results generated were analyzed using software Statistical Package for Social Sciences (SPSS) version 13.0, Microsoft coperation, Inc. Chicago, IL, USA for the calculation of percentages for categorical variables and mean for continuous data. Association between independent variables was assessed using Chi-square test and Fishers tests with appropriate Yates continuity correction. Simple logistic repression analysis was done for significantly associated variables. The reference categories for estimation of odd ratio were those patients without the risk factors of $\mathrm{HBV}$ infection with odd ratio of one. In all cases a p-value of $<0.05$ at $95 \%$ confidence interval was considered significant in statistical comparisons. 


\section{Results}

The HBsAg sero-prevalence was 50.7\%. Bivariate analysis of socio-demographic variables as related to HBsAg sero-positivity showed that socio-demographic risk factors such as age $\left(X^{2}=29.7, \mathrm{df}=2, \mathrm{P}\right.$-value $\left.=0.048\right)$ and occupation $\left(X^{2}=47.2, \quad \mathrm{df}=8, \quad \mathrm{P}\right.$-value $\left.=0.019\right) \quad$ were statistically significant. The age group $40-60$ years and artisans were significantly infected. The other sociodemographic variables such as sex, marital status, educational attainment and socio-economic class were not statistically significant. [Table1]

Table 1. Socio-demographic characteristics as related to HBsAg seropositivity

\begin{tabular}{|c|c|c|c|}
\hline Variables & $\begin{array}{l}\text { HBsAg positive } \\
\text { Number }(\%)\end{array}$ & $\begin{array}{l}\text { HBsAg negative } \\
\text { Number }(\%)\end{array}$ & P-value \\
\hline \multicolumn{4}{|l|}{ Age(years) } \\
\hline $15-39$ & $29(40.9)$ & $27(39.1)$ & \\
\hline $40-60$ & $40(56.3)$ & $30(43.5)$ & \\
\hline$>60$ & $2(2.8)$ & $12(17.4)$ & \\
\hline Total & $71(100.0)$ & $69(100.0)$ & $0.048 *$ \\
\hline \multicolumn{4}{|l|}{ Sex } \\
\hline Male & $47(66.2)$ & $38(55.1)$ & \\
\hline Female & $24(33.8)$ & $31(44.9)$ & \\
\hline Total & $71(100.0)$ & $69(100.0)$ & $0.096 * *$ \\
\hline \multicolumn{4}{|l|}{ Marital status } \\
\hline Single & $18(25.4)$ & $18(26.1)$ & \\
\hline Married & $39(54.9)$ & $14(20.3)$ & \\
\hline Separated/Divorced & $9(12.7)$ & $31(44.9)$ & \\
\hline Widowed & $5(7.0)$ & $6(8.7)$ & \\
\hline Total & $71(100.0)$ & $69(100.0)$ & $0.220 * *$ \\
\hline \multicolumn{4}{|l|}{ Educational status } \\
\hline Primary & $21(29.6)$ & $5(7.2)$ & \\
\hline Secondary & $41(57.7)$ & $55(79.8)$ & \\
\hline Post-secondary & $9(12.7)$ & $9(13.0)$ & \\
\hline Total & $71(100.0)$ & $69(100.0)$ & $0.241 * *$ \\
\hline \multicolumn{4}{|l|}{ Occupation } \\
\hline Unemployed & $6(8.5)$ & $5(7.2)$ & \\
\hline Students & $2(2.8)$ & $6(8.8)$ & \\
\hline Farmers & $2(2.8)$ & $5(7.2)$ & \\
\hline Traders & $14(19.7)$ & $16(23.2)$ & \\
\hline Artisans & $30(42.3)$ & $21(30.4)$ & \\
\hline Public servants & $6(8.4)$ & $12(17.4)$ & \\
\hline Drivers & $11(15.5)$ & $4(5.8)$ & \\
\hline Total & $71(100.0)$ & $69(100.0)$ & $0.019 *$ \\
\hline \multicolumn{4}{|l|}{ Social class } \\
\hline Lower & $67(94.4)$ & $67(97.1)$ & \\
\hline Middle & $3(4.2)$ & $2(2.9)$ & \\
\hline Upper & $1(1.4)$ & $0(0.0)$ & \\
\hline Total & $71(100.0)$ & $69(100.0)$ & $0.199 * *$ \\
\hline \multicolumn{4}{|c|}{ Family history of HBV infection } \\
\hline Yes & $13(18.3)$ & $8(11.6)$ & \\
\hline No & $58(81.7)$ & $61(88.4)$ & \\
\hline Total & $71(100.0)$ & $69(100.0)$ & $0.190 * *$ \\
\hline
\end{tabular}

Remark: *=Significant; $* *=$ Not significant

Bivariate analysis of the independent behavioural risk factors as related to $\mathrm{HBsAg}$ sero-positivity showed that histories of blood transfusion $(\mathrm{P}=0.022)$, unprotected sexual exposures $(\mathrm{P}=0.001)$ and non-hepatitis $\mathrm{B}$ vaccination $(\mathrm{P}=0.030)$ were statistically significant. The other behavioural risk factors such as histories of previous surgery and use of percutaneous sharp instruments for various purposes were not statistically significant [Table 2]

Table 2. Behavioural risk factors as related to HBsAg sero-positivity

\begin{tabular}{|c|c|c|c|}
\hline Variables & $\begin{array}{c}\text { HBsAg positive } \\
\text { Number }(\%)\end{array}$ & $\begin{array}{c}\text { HBsAg negative } \\
\text { Number }(\%)\end{array}$ & P-value \\
\hline \multicolumn{4}{|c|}{ History of blood transfusion } \\
\hline Yes & $58(81.7)$ & $3(4.4)$ & \\
\hline No & $13(18.3)$ & $66(95.6)$ & \\
\hline Total & $71(100.0)$ & $69(100.0)$ & $0.022 *$ \\
\hline \multicolumn{4}{|c|}{ History of previous surgery } \\
\hline Yes & $18(25.4)$ & $36(52.2)$ & \\
\hline No & $53(74.6)$ & $33(47.8)$ & \\
\hline Total & $71(100.0)$ & $69(100.0)$ & $0.057 * *$ \\
\hline \multicolumn{4}{|c|}{ History of unprotected sexual exposures } \\
\hline Yes & $53(74.7)$ & $43(62.3)$ & \\
\hline No & $18(25.4)$ & $26(37.7)$ & \\
\hline Total & $71(100.0)$ & $69(100.0)$ & $0.001 *$ \\
\hline \multicolumn{4}{|c|}{ History of use of percutaneous sharp instruments for various purposes } \\
\hline Yes & $69(97.2)$ & $35(50.7)$ & \\
\hline No & $2(2.8)$ & $34(49.3)$ & \\
\hline Total & $71(100.0)$ & $69(100.0)$ & $0.072 * *$ \\
\hline \multicolumn{4}{|c|}{ History of hepatitis B vaccination } \\
\hline Yes & $1(1.4)$ & $3(4.4)$ & \\
\hline No & $70(98.6)$ & $66(95.6)$ & \\
\hline Total & $71(100.0)$ & $69(100.0)$ & $0.030 *$ \\
\hline
\end{tabular}

Remark: *: Significant; **: Not significant

On simple logistic regression analysis of the statistically significant socio-demographic and behavioural independent risk factors showed that history of blood transfusion $(\mathrm{OR}=2.46, \mathrm{CI}=1.05-2.89, \mathrm{P}=0.046)$, history of unprotected sex $(\mathrm{OR}=5.04, \mathrm{CI}=3.20-6.17, \mathrm{P}=0.03)$ and history of nonhepatitis $\mathrm{B}$ vaccination $(\mathrm{OR}=2.86, \mathrm{CI}=1.06-3.73, \mathrm{P}=0.016$ remained statistically significant while age and occupation were not statistically significant [Table 3].

Table 3. Predictors of HBsAg sero-positivity among the study population.

\begin{tabular}{|c|c|c|c|}
\hline Risk factors & $\begin{array}{l}\text { Odds } \\
\text { ratio }\end{array}$ & $\begin{array}{l}\text { CI } \\
(95 \%)\end{array}$ & P-value \\
\hline $\operatorname{Age}(40-60$ years $)$ & 1.30 & $\begin{array}{l}1.06- \\
2.90\end{array}$ & $0.232 * *$ \\
\hline Occupation(Artisans) & 1.93 & $\begin{array}{l}1.08- \\
2.13\end{array}$ & $0.150 * *$ \\
\hline History of blood transfusion & 2.46 & $\begin{array}{l}1.05- \\
2.89\end{array}$ & $0.046^{*}$ \\
\hline $\begin{array}{l}\text { History of unprotected sexual } \\
\text { exposure }\end{array}$ & 5.04 & $\begin{array}{l}3.20- \\
6.17\end{array}$ & $0.003 *$ \\
\hline $\begin{array}{l}\text { History of non-hepatitis B } \\
\text { vaccination }\end{array}$ & 2.86 & $\begin{array}{l}1.06- \\
3.73\end{array}$ & $0.016^{*}$ \\
\hline
\end{tabular}

Reference categories: Age $<40$ years, Occupation(unemployed), Patients without risk factors of blood transfusion, unprotected sexual exposures and patients with history of hepatitis B vaccination. Remark: *: Significant; $* *$ : Not significant

The most significant predictor of HBsAg sero-positivity was history of unprotected sexual exposures $(\mathrm{OR}=5.04$, $\mathrm{CI}=3.20-6.17, \mathrm{P}=0.003)$.[Table 3] A significantly higher proportion of patients with history of unprotected sexual exposures(74.7\%) were HBsAg sero-positive compared to 
those without history of unprotected sexual exposures(25.3\%). Patients with history of unprotected sexual exposures were five times more likely to be $\mathrm{HBsAg}$ sero-positive compared to those without history of unprotected sexual exposures.

\section{Discussion}

The finding of HBsAg sero-prevalence of $50.7 \%$ in this study is higher than $38.0 \%$ reported in Maiduguri, Nigeria, ${ }^{[19]} 19 \%$ reported in hepatitis patients in Bangladesh [22] and $47 \%$ reported in patients with hepatocellular carcinoma in Bangladesh. ${ }^{[23]}$ However, the HBsAg sero-prevalence in this study is lower than $54.8 \%$ reported in Lagos, Nigeria by Ola et al in $2007^{[15]}$ and $58.1 \%$ reported in another study in Lagos, Nigeria by Lesi et al in 2004. ${ }^{[20] ~ T h i s ~ h i g h ~ p r e v a l e n c e ~ o f ~ H B s A g ~ i n ~ t h i s ~ s t u d y ~}$ and other studies ${ }^{[15,19,20]}$ is a reflection of the fact that these were patients who had liver diseases. The findings of this study corroborate previous reports that HBV infection exist in patients with liver diseases and may have significant relationship with liver diseases. ${ }^{[5,15,19-23]}$ However, sociodemographic and other diverse risk factors may be contributory. ${ }^{[12-14]}$ Of great concern is that HBV infection can be prevented with minimum input of resources. ${ }^{[3]}$ In fact, the developed countries of the world have overcome many of the HBV infection and HBV-related liver diseases through preventive, promotional and risk reduction interventional measures. ${ }^{[7,33]}$ When these measures are not adequately addressed in resource constrained Nigerian environment, morbidity and mortality from HBV related liver diseases may constitute an obstacle to the achievement of Millennium Development Goal as regards infectious diseases.

The finding of significantly higher sero-prevalence of HBV infection among patients aged 40-60 years is similar to the reports on the age predilection for HBV infection in Nigeria. $^{[4,12,20]}$ According to these reports, sero-prevalence of HBsAg increases with age suggesting that most infection occurs predominantly through horizontal transmission. ${ }^{[13,14]}$ However, the pattern of age distribution in this study could be a reflection of the study population who were mainly patients with liver cirrhosis and hepatocellular carcinoma. Chronic HBV infection has been documented to usually precede liver cirrhosis and hepatocellular carcinoma by a decade. ${ }^{[1,12,18-21]}$ This high sero-prevalence of HBsAg among this age group paints a gloomy picture in Nigeria, as this age group constitute the most economically biologically productive years in the Nigerian workforce who are expected to take active manpower and family responsibilities respectively. Major interventions for HBV related chronic liver diseases and promotion of appropriate health seeking behaviour for middle age patients with clinical features of liver diseases should be integrated as part of comprehensive health care protocol in primary care settings.
This study observed that artisans had significantly higher sero-prevalence of HBsAg compared with other occupational groups. This could be attributed to the clustering of risk factors among the artisans which were reported in previous studies. ${ }^{[19,34]}$ Artisans are special occupational group and often experience frequent changes of job location and socialization. ${ }^{[12]}$ The artisans are more likely to have clustering of risk factors such as history of unprotected sexual intercourse. ${ }^{[12,13]}$ In addition, the significantly higher sero-prevalence among the artisans in this study could be a reflection of the male predominance of artisan occupation. The reported gender epidemiological pattern of HBV infection in endemic areas of sub-Sahara Africa was in favour of male sex. ${ }^{[18-20]}$ Accordingly, there is a rapid decline in HBsAg titres in females resulting in a shorter duration of the carrier state. ${ }^{[35,36]}$ More so, males have poorer handling of HBV infection than the females because of the presence of immune regulatory gene on $\mathrm{X}$ chromosomes that determines susceptibility to infections. $[35,36]$

This study has shown that transfusion of infected blood play a role in the transmission mechanism of $\mathrm{HBV}$ infection among the study population. Hospital-based cross sectional studies in Nigeria ${ }^{[25,26,34]}$ and other parts of the world ${ }^{[6,37]}$ have demonstrated that HBV infection can be transmitted through blood transfusion. More so, developed countries of the world have come to demand absolute freedom from transfusion transmissible infections like HBV while conceding that zero risk blood transfusion is unlikely to be achieved. ${ }^{[37]}$ The finding of this study is therefore a call to evaluate the trend in blood donor HBV infectious disease rates in the study area. This is essential for monitoring safety of blood supply and donor screening effectiveness. However, the role of blood transfusion in the sero-epidemiology of $\mathrm{HBV}$ infection requires further investigation among these patients in the study area.

The result of this study has shown poor utilization of hepatitis B vaccination among the study population. Poor utilization of hepatitis $B$ vaccination has been reported in Jos, Nigeria. ${ }^{[25]}$ and Ile-Ife Nigeria. ${ }^{[26]}$ The poor utilization of hepatitis $B$ vaccine is a public health challenge especially in Nigeria where health promotional practices are not emphasized during clinical consultation in general practice settings. ${ }^{[38]}$ Despite advances in antiviral or interferon therapy which is presently unaffordable in Nigeria, only a small percent of patients with chronic HBV infection have a sustained response to these drugs. ${ }^{[33,39]}$ Thus, primary prevention strategies including hepatitis B vaccination to increases the immunity to $\mathrm{HBV}$ infection remain the main thrust in control of $\mathrm{HBV}$ infection in the study area.

The most significant predictor of HBV infection was sexual risk factor. History of unprotected sexual exposures in the transmission dynamics of HBV infection have been reported in different parts of Nigeria such as Ile-Ife, Nigeria where $20.0 \%$ of the respondents reported history of 
unprotected sexual exposures, ${ }^{[26]}$ and in Jos, Nigeria where prevalence of $46.5 \%$ was reported. ${ }^{[25]}$ Similarly, various frequencies of $\mathrm{HBV}$-related sexual risk factors have been reported in different parts of the world like in Egypt where $50.0 \%$ was reported, ${ }^{[27]}$ in Bangladesh $9.7 \%$ was reported ${ }^{[28]}$ and $51.0 \%$ was reported in Bucharest. ${ }^{[29]}$ The finding of this study has suggested that the identified independent risk factor of unprotected sexual exposures could provide a direction and guide for health education, counselling and health promotion when consulting with patients with clinical features of liver diseases in primary care settings in the study area.

\subsection{Study Implications}

In resource-poor nations such as Nigeria, utilization of HBV screening tests such as HBsAg serological test for patients with clinical features of liver diseases is relatively poor and assessing for the socio-demographic and behavioural risk factors of $\mathrm{HBV}$ infection during clinical consultation with patients with clinical features of liver diseases in primary care setting is usually suboptimal. However, detection of HBsAg in the serum of patients with clinical features of liver diseases and obtaining relevant bio-social risk factors are usually informative and should provide direction for further diagnostic work-up, health education, risk reduction and health promotion in primary care. Although, the detection of serological bio-marker (HBsAg) of HBV infection bears little relation to the severity of clinical liver diseases, however, this research finding is important for clinical and public health practice in the study area. This study therefore envisaged the challenges of primary care delivery to adult patients with clinical features of liver diseases with implications for quality improvement in resource-constrained environment where HBV infection is endemic.

\subsection{Study Limitations}

The study had certain constraints which imposed some degree of limitations to the absolute validity of the results. This study was hospital-based, as only patients who presented to the hospital were studied. Some of the patients with HBV-related liver diseases patronize traditional and spiritual healing homes, patent medicine vendor stores and private clinics closer to their homes. However, because of the hospital-based nature of this study bias might have been introduced and might not be a true representative of what happens in the community; hence extrapolations to the communities should be done with caution.

The limitation imposed by the descriptive nature of the study is recognized by the researchers. However, this study stimulates the need for analytical and longitudinal studies in this area. This would enable a quasi cause-effect relationship to be drawn and also for a reliable and valid conclusion to be ascertained.

The sample size was relatively small, but this was more than the minimum estimated sample size for the study and was the number of patients seen within the study period.

This study was based on testing of sera samples for HBsAg only which doesn't fully reflect the epidemiology of HBV-related liver disease. ${ }^{[10,14]}$ If other serologic markers of $\mathrm{HBV}$ infection such as $\mathrm{HBeAg}$, anti-HBs, HBV DNA and anti-HBc were assayed, the actual prevalence would probably be much higher than the present reported figures.

More so, although rapid sero-diagnostic test kits based on immunochromatographic principles are very sensitive, not all infections in the acute phase were probably detected. It was also possible that an infectious individual early in the incubation phase would not have sero-converted when tested. Similarly, several types of immunological tests such as Western blot, enzyme linked immunosorbent assay (ELISA) method and PCR-DNA based assay are currently used for detection of HBV infection. In this study, the use of rapid sero-diagnostic tests based on chromatographic immunoassays technique, though found to be less sensitive than other counter immunoelectrophoretic principle (CIEP), can provide prompt epidemiological data for primary care physicians, community physicians and health authorities. It can also deliver an immediate useful feedback to research participants and the outcomes may assist in improving local understanding of HBV infection in resource-poor settings.

The case selection in this study was based on clinical parameters. However, histopathological studies were not done due to the objectives, setting and scope of the study. Despite this limitation, this study provides valuable information which can be utilized in primary care settings especially in resource constrained setting for adopting appropriate interventional measures.

\section{Conclusion}

Risk factors of hepatitis B virus infection exist in adult Nigerian patients with clinical features of liver diseases and $\mathrm{HBV}$ infection is associated with risk factors such as age, occupation and histories of unprotected sexual exposures, blood transfusion and non-hepatitis $\mathrm{B}$ vaccination. Screening adult Nigerians with clinical features of liver diseases for HBV infection and inquiring for its associated biosocial risk factors is recommended in primary care settings.

\section{References}

[1] Shepard CW, Simard EP, Finelli L, Fiore AE, Bell BP. Hepatitis B virus infection: Epidemiology and vaccination. Epidemiol Rev 2006; 28: 112 - 25.

[2] Alter MJ. Epidemiology of hepatitis B infection in Europe and worldwide, J. Hepatol. 2003; 39: 64-9.

[3] Zukerman AJ. More than third of world's population has been infected with hepatitis B virus [Letter]. BMJ 1999; 318: 1213. 
[4] Emechebe GO, Emodi IJ, Ikefuna AN, Ilechukwu GC, Igwe WC, Ejiofor OS, Ilechukwu CA. Hepatitis B Virus Infection in Nigeria - A Review. Niger Med J 2009; 1: 18 - 22.

[5] Ola SO. Relief to the scourge of primary hepatocellular carcinoma. Niger J Med 2002; 11: 156-60.

[6] Das BK, Gayen BK, Aditya S, Chakrovorty SK, Datta PK, Joseph A. Seroprevalence of Hepatitis B, Hepatitis C, and human immunodeficiency virus among healthy voluntary first-time blood donors in Kolkata. Ann Trop Med Public Health $2011 ; 4$ : 86-90

[7] Omata M, Dan Y, Damele B, Plentz R, Rudolph K, Manns M. Clinical features, etiology and survival of hepatocellular carcinoma among different countries. J Gastroenterol. Hepatol 2002; 17(Suppl): 40-9.

[8] Sakhuja P, Malhotra V, Gondal R, Sarin SK, Gupta R, Thakur V. Histological spectrum of chronic hepatitis in precore mutants and wild type hepatitis B virus infection. Trop Doct 2004; 34: 147-8.

[9] Hayashi PH, Di Bisceglie AM. The progression of hepatitis $\mathrm{B}$ and $\mathrm{C}$ infections to chronic liver disease and hepatocellular carcinoma: epidemiology and pathogenesis. Med Clin North Am 2005; 89: 371-89.

[10] Ndububa DA, Ojo OS, Adetiloye VA, Durosnmi MA Olasode BJ, Famurewa OC, et al. Chronic hepatitis in Nigerian patients: A study of 70 biopsy-proven cases. West Afr J Med 2005; 24: 107-11.

[11] Lesi OA, Kehinde MO, Omilabu SA. Prevalence of the $\mathrm{HBeAg}$ in Nigerian patients with chronic liver disease. Niger Qt Hosp Med 2004; 14: 1 - 4.

[12] Sirisena ND, Njoku MO, Idoko JA. Carriage rate of HBsAg in an urban community in Jos, Plateau State. Niger Postgrad Med J 2002; 9: 7-10.

[13] Jumbo GTA, Egah DZ, Banwat EB. Hepatitis B virus infection in a rural settlement of Northern Nigeria. Niger J Med 2005; 14: 425-8.

[14] Ejele OA, Ojule AC. Hepatitis B antigenaemia (HBsAg): Risk of occupational exposure in a chemical pathology laboratory in Nigeria. Niger J Clin Pract 2003; 6: 99-101.

[15] Ola SO, Odaibo GN. Alfa-feto protein, HCV and HBV infections in Nigerian patients with primary hepatocellular carcinoma. Niger Med Pract 2007; 51: 33-5.

[16] Ogunbiyi JO. Hepatocellular carcinoma in developing world, Semin Oncol 2001; 28:179-87.

[17] Adeniji KA, Anjorin AS. The pattern of malignant tumors of the Liver in a tertiary health institution in Nigeria. Afr J Med Sci 2004; 33: 27-30.

[18] Abdulkareem FB, Banjo AAF, Elesha SO, Daramola AO. Histopathological study of liver diseases at the Lagos University Teaching Hospital, Nigeria: 1989-2000. Niger Postgrad Med J 2006; 13: 41-6.

[19] Baba MM, Ajayi BB, Ekanem LA. Prevalence of HBsAg among patients suspected of liver diseases in a Nigerian hospital. Niger Postgrad Med J 2000; 7: 91- 5.

[20] Lesi. OA, Kehinde MO, Anomneze EE. Chronic liver disease in Lagos: A clinicopathological study. Niger
Postgrad Med J 2004; 11: 91-6.

[21] Ola SO, Otagbeyo JA, Odaibo GN, Olaleye OD, Olubuyide OI. Serum hepatitis $\mathrm{C}$ virus and HBsAg in Nigerian patients with acute icteric hepatitis. West Afr J Med 2002; 21: 21517.

[22] Khan WI, Sultana R, Rahman M, Akhter H, Haq JA, Mohsin MA, Khan AK. Viral hepatitis: recent experiences from serological studies in Bangladesh. Asian Pac J allergy Immunol 2000; 18: 99-103.

[23] Khan M, Haq S, Ahmed N, Matin MA. Etilogy and clinical profile of hepatocellular carcinoma in Bangladesh. Bangladesh Med Res Counc Bull 1997; 23: 16-24.

[24] Lavanchy D. Hepatitis B virus epidemiology, disease burden, treatment and current and emerging prevention and control measures: A review. J Viral Hepat 2004; 2: 97 - 107.

[25] Iroezindu MO, Daniyam CA, Isa ES, Okeke EN, Agbaji OO. High-risk behaviour among hepatitis B virus-infected patients in Nigerian tertiary hospital. Jos Journal of Medicine 2012; 6: 8-12.

[26] Adekanle O, Ndububa DA, Ayodeji OO, Paul-Odo B, Folorunso TA. Sexual transmission of the hepatitis B virus among blood donors in a tertiary hospital in Nigeria. Singapore Med J 2010; 51: 944-47.

[27] Jimenez AP, El-Din NS, El-Hoseiny M, El-Daly M, AbdelHamid M, El-Aidi S, et al. Community transmission of hepatitis B virus in Egypt: results from a case-control study in Greater Cairo. International Journal of Epidemiology 2009; 38: 757-65.

[28] Sattar H, Islam MN. Hepatitis B virus markers among the prostitutes of Dhaka. Bangladesh Med Res Counc Bull 1996; 22: 8-11.

[29] Ion-Nedelcu N, Iordachescu C, Gherasim P, Mihailovici R, Dragomirescu C, Dumitrache-Marian R, et al. Prevalence of risk factors and mechanisms of transmission of acute viral hepatitis type B and C in Bucharest municipality: 20012008. Bacteriol Virusol Parazitol Epidemiol 2009; 54: 103-8.

[30] Ibrahim T. Sample size determination. In: Research Methodology and Dissertation writing for Health and Allied Health Professionals. Abuja, Nigeria Cress Global Link Limited; 2009: 70-75.

[31] Araoye MO. Sample size determination. Research Methodology with Statistics for Health and Social Sciences, Ilorin, Nathadex Publishers, 2004. P.115- 21.

[32] Omoigberale AI, Airauhi LU. Aspects of the epidemiology of intestinal parasitoses(IP) in children: knowledge, practices and perceptions of mothers. Niger J Clin Pract 2006; 9:109-13.

[33] Hoofnagle JH. Hepatitis B: preventable and now treatable. New Engl J Med 2006; 354: 1074- 76.

[34] Ola SO, Jaiyesimi AEA, Olusanya OO. Co-infection of human immunodeficiency virus and hepatitis B virus among Nigerian patients and blood donors at Sagamu. Niger Med J 2005; 46: 64-7.

[35] Hyams KC. Risk of chronicity following acute hepatitis B virus infection: a review. Clin Infect Dis 1997; 20: 9921000. 
[36] Sherlock S, Dooley J. Diseases of the Liver and Biliary Sysem. Oxford, Blackwell Publishers 2002. p. 294.

[37] Glynn AS, Kleinman SH, Schreiber GB, Bush MP, Wright DJ, Smith JW et al. Trends in the incidence and prevalence of major transfusion transmissible viral infection in the USA, JAMA 2000; 284:229-30.
[38] Iyaniwura CA. Health Promotion in General Medical Practice in Ogun State. Niger Med Pract 2004; 45: 29-32.

[39] Ola SO, Anomneze EE, Chukwuani CM, Ojo SC, Ndububa DA, Onyekwere B, etal: Interferon alpha-2a (Roferon) in the Management of chronic hepatitis B infection; Results of an open prospective study in Nigerian patients, West Afr J Med 2000; 19: 259-64. 